\title{
Systematic Analysis of Branching Patterns of Three Almond Cultivars with Different Tree Architectures
}

\author{
Claudia Negrón, Loreto Contador, Bruce D. Lampinen, Samuel G. Metcalf, and \\ Theodore M. DeJong ${ }^{1}$ \\ University of California, Department of Plant Sciences, One Shields Avenue, Davis, CA 95616 \\ Yann Guédon \\ Virtual Planats INRIA Team, UMR AGAP CIRAD/INRA/Montpellier SupAgro, Avenue Agropolis, \\ TA-A-108/03, 34398 Montpellier Cedex 5, France \\ Evelyne Costes \\ Architecture and Functions of Fruit Trees Team, UMR AGAP CIRAD/INRA/Montpellier SupAgro, \\ Avenue Agropolis, TA-A-108/03, 34398 Montpellier Cedex 5, France
}

\begin{abstract}
Additional Index words. flowering, hidden semi-Markov model, proleptic shoot, Prunus dulcis, shoot structure, sylleptic shoot

Abstract. Different almond (Prunus dulcis) cultivars have been characterized by their contrasting shoot branching patterns; however, the differences between patterns have been difficult to quantify. This study aimed to model the branching patterns of 2-year-old proleptic shoots on three almond cultivars (Nonpareil, Aldrich, and Winters) representing different tree architectures. The effects of branching pattern on flowering were also studied. The branching patterns of shoots of different length categories were assessed by a single hidden semi-Markov model for each cultivar. The models identified zones of homogeneous branching composition along shoots and were used to extract the occurrence and number of nodes of the zones according to shoot length categories. The numbers of flower buds were also determined for each shoot length category in each cultivar. The models of branching patterns of 'Nonpareil' and 'Aldrich' were similar and differed from the 'Winters' model. 'Winters' shoots produced more zones, but some of the zones had similar characteristics as previous zones and thus appeared to be repeated. This cultivar also had more spurs and sylleptic shoots than the other cultivars. The occurrence and node number of the central zones decreased along with reduction in shoot length in all the cultivars. 'Aldrich' tended to have more flower buds than comparable-length shoots of the other two cultivars. This study provides a quantitative description of the shoot branching patterns of three important cultivars and explains how branching changes in relation to shoot length, whereas production of flower buds varies despite similar branching patterns.
\end{abstract}

Almond trees develop fruit laterally on extension shoots and short shoots called spurs on 2-year-old or older wood (Kester et al., 1996). The pattern of shoots and spurs along branches is of major importance because they determine tree architecture and cropping potential (Bernad and Socias i Company, 1998). In almond, diverse tree architectures among cultivars are mainly the result of their genetically determined branching patterns rather than pruning practices because trees are usually minimally pruned to maximize yield (Gradziel, 2012). Previous characterization of almond branching patterns has been based on the degree and type of lateral branching in the previous and current growing season in different cultivars (Gradziel et al., 2002). However, those patterns have not been well quantified. Branching patterns of shoots range from total suppression of lateral sylleptic and proleptic shoot production, resulting in whip-like shoots, to little lateral suppression of sylleptic and proleptic shoots, resulting in highly branched shoots (Gradziel et al., 2002).

Three types of shoots developed on a 2-year-old shoot according to their dormant time and length: proleptic, or

Received for publication 16 July 2013. Accepted for publication 9 Sept. 2013. We thank the grower, Bard Anderson, for providing the study site, Dr. Franz Niederholzer for logistic support, and Dr. Thomas Gradziel for discussions on cultivar's architecture.

${ }^{1}$ Corresponding author. E-mail: tmdejong@ucdavis.edu. "delayed," shoots originating from axillary meristems after a dormant period; sylleptic shoots, or "immediate laterals," elongating from axillary meristems immediately after their initiation without any evident period of rest (Barthélémy and Caraglio, 2007); and spurs that are proleptic shoots with minimal elongation of the internodes and constitute the main fruitbearing shoot type in mature almond trees (Kester et al., 1996). Spurs produce up to six lateral floral buds (Polito et al., 2002) and typically remain viable for 3 to 5 years (Weinbaum and Spiegel-Roy, 1985). Sylleptic branching of most almond cultivars in California is moderate and this is considered commercially desirable (Gradziel et al., 2002). This moderate branching allows for an open tree architecture and permits opportunities for fruit wood renewal without excessive shading of the interior canopy (Kester et al., 1991).

Hallé et al. (1978) developed a scheme to describe branch and tree architecture of tropical trees that has been applied to many tropical and temperate tree species (Costes et al., 2006; Fisher, 1984). These analyses have helped to identify genetically determined branching patterns involved in plant construction (Barthélémy and Caraglio, 2007). This led to studies of branching patterns using stochastic models, especially in apple [Malus $\times$ domestica (Costes and Guédon, 1996, 2002; Renton et al., 2006)]. In particular, hidden semi-Markov models have been used to describe the organization of lateral meristem fates in a succession of zones along shoots, where each zone has 
a characteristic composition of observation types such as shoots, spurs, blind nodes, or others (Guédon et al., 2001). These branching studies usually are conducted after the second growing season of shoot development, after sylleptic and proleptic shoots have developed (Costes and Guédon, 2002; Renton et al., 2006).

In the present study, three almond cultivars, which have been described as having different tree architectures, were selected for analysis of branching patterns using the hidden semi-Markov models. 'Nonpareil' is the most important cultivar in California (U.S. Department of Agriculture, 2011). This cultivar has consistent and high productivity, bearing on both spurs and long shoots (Asai et al., 1996). The tree is large and upright to spreading with limited lateral shoot development on both 1- and 2-year-old shoots (Gradziel et al., 2002). 'Aldrich' is a large and upright tree (Gradziel, 1997), with sparse sylleptic branching but copious production of proleptic spurs and subsequent blooms (Aldrich, 1984). In contrast, 'Winters' has an upright and highly branching architecture. Production occurs on spurs, on terminal 1-year-old shoots, and on characteristic, medium-short sylleptic shoots ranging in length from 5 to $20 \mathrm{~cm}$. Gradziel et al. (2007) suggested that this type of shoot increases fruit wood renewal and may promote high and consistent productivity as well as producing an open tree architecture that favors light penetration to the canopy interior.

This study aimed at characterizing the branching patterns of 2-year-old proleptic shoots of these three almond cultivars (Nonpareil, Aldrich, and Winters) with contrasting tree architectures and analyzing the effect of these patterns on flowering. All observation types (i.e., blind nodes, spurs, proleptic and sylleptic shoots) and the number of flower buds on 2-year-old proleptic shoots of different length categories were assessed to determine whether cultivars have shoots with different branching patterns and flowering. Thus, in this study specifically 1) branching patterns were modeled by a single hidden semiMarkov model of different shoot lengths for each cultivar; 2) the models of each cultivar were used to evaluate gradients in branching patterns among shoots of different lengths; and 3) the numbers of flower buds were determined on each shoot length category in each cultivar.

\section{Materials and Methods}

The research was conducted in 2010 in a commercial, producing almond orchard planted in 2006 and located near Sutter (lat. $39^{\circ} 09^{\prime} \mathrm{N}$, long. $121^{\circ} 45^{\prime} \mathrm{W}$ ) in California's Central Valley. This orchard had three cultivars (Nonpareil, Aldrich, and Winters). Every cultivar was planted in rows oriented north to south, where a 'Nonpareil' row had a row of each of the other cultivars to each side. Trees in the orchard were minimally pruned after 2007, when the main scaffolds were chosen, so that trees developed their architecture naturally.

In every cultivar, evaluations were executed on 2-year-old proleptic shoots that grew from terminal buds on unpruned branches. The 2-year-old proleptic shoots in the tree canopies were organized into five length categories: "long" shoots (more than $100 \mathrm{~cm}$ ), "medium-long" shoots (between 60 and $100 \mathrm{~cm}$ ), "medium" shoots (between 20 and $60 \mathrm{~cm}$ ), "medium-short" shoots (between 5 and $20 \mathrm{~cm}$ ), and "short" shoots (less than $5 \mathrm{~cm}$ ). In Feb. 2010, one example of each shoot length category was randomly selected on the upper half of 10 trees per cultivar in each of their quadrants (northeast, northwest, southeast, and southwest), totaling 40 shoots per category of each cultivar.
Lateral branching of the tagged 2-year-old proleptic shoots was evaluated by recording the observation type at every node from the tip to the base of the shoot before bloom. Shoots were described in this order because branching is apically controlled (Wilson, 2000). Four observation types were described at each node: blind node (lack of an axillary meristem), spur, proleptic shoot, or sylleptic shoot (Fig. 1).

In a first data analysis of observation types without regard to structure, the total numbers of the different observations per shoot were compared among cultivars using the WilcoxonMann-Whitney test $(P \leq 0.05)$ because data did not meet the assumption of normality. For the branching pattern analysis, observation types at each node along the shoot were organized in the same direction as data were collected (i.e., from the tip to the base of the shoot). This succession of observation types along the shoot was represented as a discrete sequence of data indexed by the node rank. An exploratory analysis of the branching patterns of the different shoot length categories was conducted for each cultivar. This analysis was mainly based on empirical intensity distributions that indicated the probability of each observation type at each node rank (Costes and Guédon, 1997, 2002). The intensity distributions indicated zones of homogenous observation types along the shoots and a progressive reduction of the number of zones as the shoots decreased in length. Based on these characteristics, a single hidden semiMarkov model for each cultivar was built to model the branching patterns of all shoot length categories. Hidden semi-Markov models have been used in previous studies to model branching patterns in different species. For a complete description of these models, see Guédon et al. (2001).

In the present study, the hidden semi-Markov models for each cultivar were estimated using an iterative algorithm,

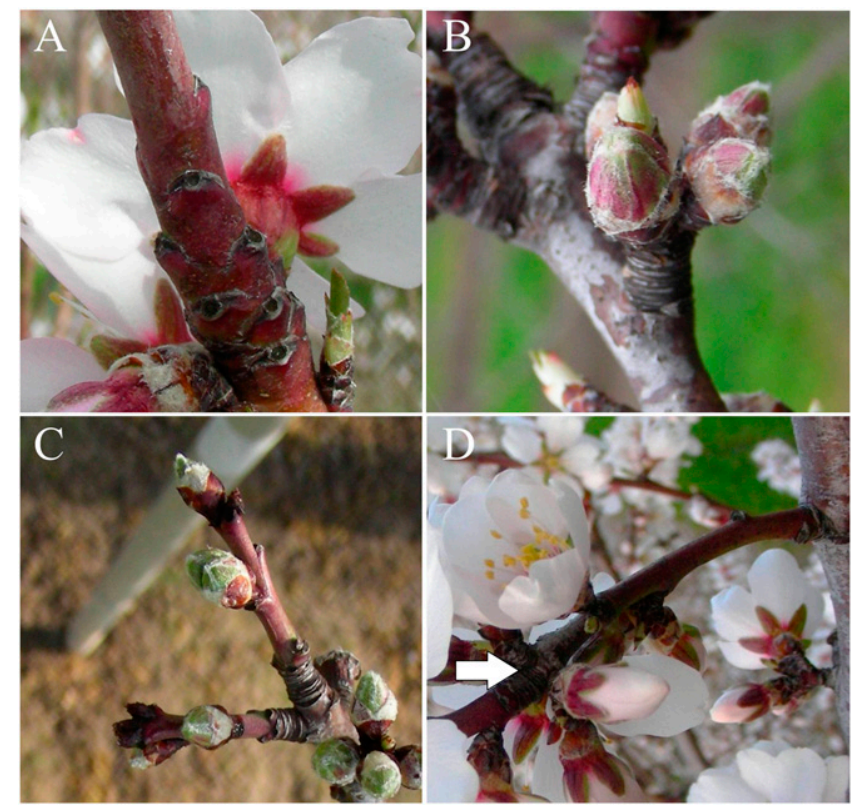

Fig. 1. Observation types (i.e., blind nodes, spurs, proleptic and sylleptic shoots) on a 2-year-old proleptic shoot in almond. (A) Group of blind nodes that lack buds. (B) One-year-old spur with four floral buds. (C) One-year-old lateral and apical proleptic shoots. (D) Two-year-old sylleptic shoot that grew in the same season as the evaluated 2-year-old proleptic shoot. The ring of bud scale scars at the left of this figure (see arrow) indicates the start of the 1-year-old proleptic shoot that grew from the apical bud of the sylleptic shoot. 
which maximized the likelihood of the observed sequences, starting with assumptions established in an initial model. The initial models relied on assumptions drawn from the empirical intensity distributions regarding the number of zones in the shoots, the succession of the zones, and the presence of observation types in each zone. To evaluate the accuracy of the estimated hidden semi-Markov models, theoretical distributions estimated from model parameters were plotted along with the empirical distributions extracted from the observed sequences (Guédon et al., 2001). In 'Nonpareil' and 'Aldrich', initial models with seven states (i.e., seven zones within the shoots) were used in the estimation procedure. The successions of states in the models were unidirectional (i.e., only transitions from one state to the next were allowed, but transitions from a given state to the previous ones were forbidden). The states were thus ordered with a succession of transient states (a state is said to be transient if when leaving it, it is impossible to return to it) and a final absorbing end state. In 'Winters', an 11-state initial model with ordered states was first used for the estimation of a model. In the estimated model, States 3, 4, and 5 had similar observation probabilities as States 6, 7, and 8, respectively. Therefore, in this cultivar, a seven-state initial model with three recurrent states was used (i.e., transitions from State 5 to State 3 were allowed) in the estimation procedure. The states were thus partially ordered with both transient and recurrent states and a final absorbing end state. For all the cultivars, the presence of each observation type was permitted in every zone, except in the apical and basal zones of the shoots, where only blind nodes were observed.

From the models for each cultivar, specific parameters for the shoots from each shoot length category were extracted. To do this, the most probable state sequence for each observed sequence was computed using the hidden semi-Markov model of each cultivar. This new sequence corresponded to the optimal segmentation according to the homogenous zones of the observed sequence. Subsequently, the most probable state sequences, along with observed sequences, were grouped according to the shoot length category in which the shoot was originally assigned. Finally, the segmentation of each shoot was used to obtain the occurrence of each zone along the shoot and the number of nodes per zone for each shoot length category.

On the same 2-year-old tagged proleptic shoots on which branching was evaluated, the total number of flower buds per shoot by length category was assessed. The total number of flower buds included the flower buds on 1-year-old spurs and on 1-year-old proleptic and sylleptic shoots. The number of flower buds per shoot was compared among cultivars for each length category with the non-parametric WilcoxonMann-Whitney test $(P \leq 0.05)$, because the data were not normally distributed.

The exploratory analysis of the sequences of data collected from the shoots was conducted using VPlants software, part of the OpenAlea platform (Pradal et al., 2008), the successor of AMAPmod (Godin et al., 1997). This software was also used to estimate the models and to extract the occurrence of each zone along the shoot and the number of nodes per zone. All statistical comparison tests were conducted with SAS (Version 9.2; SAS Institute, Cary, NC).

\section{Results}

Fewer lateral shoots were observed with reductions in the length of the evaluated 2-year-old shoots (Table 1). The number of spurs and proleptic and sylleptic shoots was more similar between 'Nonpareil' and 'Aldrich' as compared with 'Winters'. 'Winters' generally had more spurs and sylleptic shoots, and fewer proleptic shoots, than the other two cultivars. In 'Winters' and 'Nonpareil', shoots had more blind nodes than 'Aldrich', except for medium and medium-short shoots. 'Winters' also had more or equal numbers of nodes as the other cultivars for a given shoot length category.

Differences among cultivars in observation types along the shoots were highlighted by intensity plots for each cultivar and shoot length category (Fig. 2). These plots indicate different zones along the shoots. Zone compositions were defined by a mixture of observation types, but generally a single observation type was the main observation. In 'Nonpareil' long shoots, the zone at the tip of the shoot had only blind nodes and was close to a zone with a high probability of proleptic shoots. This was followed by a third zone with a high probability of spurs and another zone with blind nodes. The fifth zone had a high probability of spurs and some sylleptic shoots. Finally the zone at the base of the shoots had mainly blind nodes (Fig. 2A). Long shoots in 'Aldrich' (Fig. 2B) had a more similar distribution of observation types to 'Nonpareil' than to 'Winters'. The distribution in 'Winters' was quite different with more zones along the shoots (Fig. 2C). As shoots decreased in length, fewer

Table 1. Mean number of observation types (blind nodes, spurs, proleptic and sylleptic shoots) and mean total number of nodes of 2-year-old shoots of five different length categories in three almond cultivars (Nonpareil, Aldrich, Winters).

\begin{tabular}{|c|c|c|c|c|c|c|}
\hline Cultivar & $\begin{array}{l}\text { Shoot length } \\
\text { category }^{\mathrm{z}}\end{array}$ & $\begin{array}{c}\text { Blind } \\
\text { nodes (no.) }\end{array}$ & Spurs (no.) & $\begin{array}{c}\text { Proleptic } \\
\text { shoots (no.) }\end{array}$ & $\begin{array}{c}\text { Sylleptic } \\
\text { shoots (no.) }\end{array}$ & $\begin{array}{l}\text { Total } \\
\text { (no.) }\end{array}$ \\
\hline Nonpareil & Long & $22.32 \mathrm{a}^{\mathrm{y}}$ & $42.92 \mathrm{a}$ & $19.97 \mathrm{a}$ & $3.13 \mathrm{~b}$ & $88.34 \mathrm{a}$ \\
\hline Aldrich & & $13.29 \mathrm{~b}$ & $38.32 \mathrm{~b}$ & $19.16 \mathrm{a}$ & $3.45 \mathrm{~b}$ & $74.21 \mathrm{~b}$ \\
\hline Winters & & $23.16 \mathrm{a}$ & $42.45 \mathrm{a}$ & $6.21 \mathrm{~b}$ & $18.34 \mathrm{a}$ & $89.89 \mathrm{a}$ \\
\hline Nonpareil & Medium-long & $23.37 \mathrm{a}$ & $29.24 \mathrm{c}$ & $10.58 \mathrm{a}$ & $0.37 \mathrm{~b}$ & $63.55 \mathrm{~b}$ \\
\hline Aldrich & & $16.11 \mathrm{~b}$ & $34.89 \mathrm{~b}$ & $9.74 \mathrm{a}$ & $0.08 \mathrm{c}$ & $60.82 \mathrm{~b}$ \\
\hline Winters & & $24.18 \mathrm{a}$ & $41.68 \mathrm{a}$ & $4.61 \mathrm{~b}$ & $4.95 \mathrm{a}$ & $75.42 \mathrm{a}$ \\
\hline Nonpareil & Medium & $12.66 \mathrm{~b}$ & $14.58 \mathrm{c}$ & $1.79 \mathrm{a}$ & $0.00 \mathrm{~b}$ & $29.03 \mathrm{~b}$ \\
\hline Aldrich & & $17.11 \mathrm{a}$ & $18.87 \mathrm{~b}$ & $1.95 \mathrm{a}$ & $0.00 \mathrm{~b}$ & $37.92 \mathrm{a}$ \\
\hline Winters & & $12.03 \mathrm{~b}$ & $24.00 \mathrm{a}$ & $0.32 \mathrm{~b}$ & $0.97 \mathrm{a}$ & $37.32 \mathrm{a}$ \\
\hline Nonpareil & Medium-short & $9.97 \mathrm{a}$ & $4.63 \mathrm{~b}$ & $0.11 \mathrm{a}$ & $0.00 \mathrm{a}$ & $14.71 \mathrm{~b}$ \\
\hline Aldrich & & $9.76 \mathrm{a}$ & $5.84 \mathrm{~b}$ & $0.05 \mathrm{a}$ & $0.00 \mathrm{a}$ & $15.66 \mathrm{~b}$ \\
\hline Winters & & $9.34 \mathrm{a}$ & $10.53 \mathrm{a}$ & $0.00 \mathrm{a}$ & $0.00 \mathrm{a}$ & $19.87 \mathrm{a}$ \\
\hline Nonpareil & Short & $8.03 \mathrm{a}$ & $1.16 \mathrm{~b}$ & $0.00 \mathrm{a}$ & $0.00 \mathrm{a}$ & $9.18 \mathrm{~b}$ \\
\hline Aldrich & & $6.74 \mathrm{~b}$ & $1.00 \mathrm{~b}$ & $0.00 \mathrm{a}$ & $0.00 \mathrm{a}$ & $7.74 \mathrm{c}$ \\
\hline Winters & & $7.84 \mathrm{a}$ & $2.71 \mathrm{a}$ & $0.00 \mathrm{a}$ & $0.00 \mathrm{a}$ & $10.55 \mathrm{a}$ \\
\hline
\end{tabular}

${ }^{\mathrm{z}}$ Shoot length categories were long (more than $\left.100 \mathrm{~cm}\right)$, medium-long (60 to $\left.100 \mathrm{~cm}\right)$, medium (20 to $60 \mathrm{~cm}$ ), medium-short ( 5 to $20 \mathrm{~cm}$ ), and short (less than $5 \mathrm{~cm}$ ).

${ }^{y}$ Letter indicates difference among cultivars for each shoot length category according to the Wilcoxon-Mann-Whitney test at $P \leq 0.05$. 


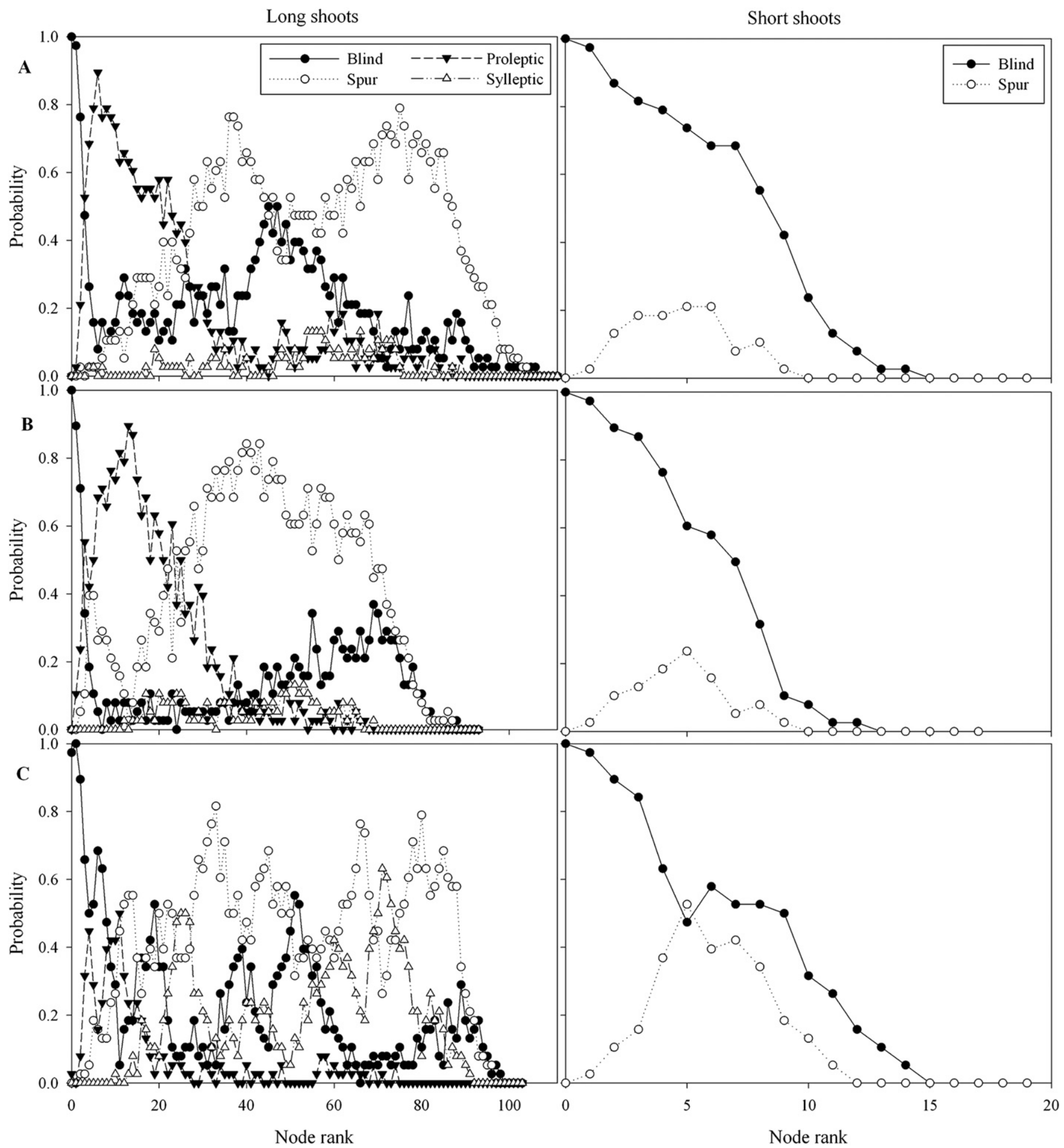

Fig. 2. Probability of the different observation types (blind nodes, spurs, proleptic and sylleptic shoots) at each node rank of 2-year-old long (more than $100 \mathrm{~cm}$ ) and short (less than $5 \mathrm{~cm}$ ) almond shoots in (A) 'Nonpareil', (B) 'Aldrich', and (C) 'Winters'. Node rank 0 corresponds to last node before the 1-year-old shoot. Increment in node rank indicates location of the node toward the base of the shoots.

zones were present. On short shoots in all the cultivars, three zones were observed on the intensity plots. The basal and tip zones only had blind nodes, whereas the central zone had a mixture of spurs and blind nodes (Fig. 2A-C).

The hidden semi-Markov model for the lateral branching of each cultivar including shoots from all length categories is shown in Figure 3. In 'Nonpareil', the model was composed of six transient states that represent the zones of the shoot. An absorbing state (i.e., the final state of the model) represented the 3 -year-old shoot, from which the evaluated shoot originated (Fig. 3A). The zones were defined based on their corresponding observation distributions: 1) Zone 0 at the tip of the shoots had 



Main characteristic of each zone

Only blind nodes
Code for lateral type

B: Blind node; Sp: Spur; P: Proleptic shoots; S: Sylleptic shoots

Fig. 3. Schematic representation of hidden semi-Markov models for 2-year-old almond shoots on (A) 'Nonpareil', (B) 'Aldrich', and (C) 'Winters' including the different shoot length categories per cultivar [long (more than $100 \mathrm{~cm})$, medium-long (60 to $100 \mathrm{~cm}$ ), medium $(20$ to $60 \mathrm{~cm})$, medium-short $(5$ to $20 \mathrm{~cm})$, and short (less than $5 \mathrm{~cm}$ )]. Zone at the top of the shoots (Zone 0 ) is at the right of the schema and the zone that represents the 3-year-old shoot (Zone 6 for 'Nonpareil' and 'Aldrich'; and Zone 7 for 'Winters') is at the left. The zones of the shoots are represented by rectangles where the different crosshatching patterns indicate the main branching characteristics. The mean node number per zone is indicated in the center of each rectangle. The transitions between zones are shown by connecting arrows and the probabilities of transition are shown near each arrow. The observation types and their probabilities within a zone are indicated below each rectangle. The diagram shows observations that had probabilities greater than 0.01 . 
only blind nodes; 2) Zone 1 had mainly proleptic shoots with some blind nodes and spurs; 3 ) Zone 2 was a mixture of all the observations where spurs had the highest probability of occurrence and sylleptic shoots the lowest; 4) Zone 3 had mainly blind nodes and some spurs; 5) Zone 4 had a similar composition to Zone 2 with higher probability of occurrence of spurs and sylleptic shoots than Zone 2;6) Zone 5, located at the base of the shoots, had only blind nodes; and 7) Zone 6 represented the 3-year-old shoot. The transition probabilities between zones indicated that the central zones were not present on all shoots (Fig. 3A). The probabilities of zone occurrence calculated for each shoot length category from the model of each cultivar indicated that the central zones were less likely to be present on shorter shoots (Table 2). Zones with blind nodes at the base and at the tip of shoots had similar and high probabilities of occurrence in all the shoot categories. Zone 1, composed mainly of proleptic shoots, was always observed on long shoots but was never observed on medium-short and short shoots. Zone 2 was the least probable on all shoots and was absent in shorter shoots. Zones 3 and 4 were observed in all shoot categories, but the probabilities of occurrence on shorter shoots were lower than on longer shoots. The mean number of nodes per zone varied according to the composition of the zone and to the length of the shoot (Table 2). In zones composed mainly of blind nodes (Zones 0,3 , and 5 ), the number of nodes was relatively constant among shoot length categories. In contrast, the mean number of nodes of Zones 1, 2, and 4, composed mainly of spurs and proleptic and sylleptic shoots, decreased along with shoot lengths.

The branching patterns in 'Aldrich' were modeled with a hidden semi-Markov model similar to the one used for 'Nonpareil' (Fig. 3B). Both models had the same number of zones but with different transition probabilities between zones.

Table 2. Probability of zone occurrence and mean number of nodes per zone for five different shoot length categories (L, ML, M, MS, S) in three almond cultivars (Nonpareil, Aldrich, Winters).

\begin{tabular}{|c|c|c|c|c|c|c|c|c|c|c|c|}
\hline \multirow[b]{2}{*}{ Cultivar } & \multirow[b]{2}{*}{ Zone $^{\mathrm{z}}$} & \multicolumn{5}{|c|}{ Zone occurrence $(P)$} & \multicolumn{5}{|c|}{ Nodes (no.) } \\
\hline & & $\mathrm{L}^{\mathrm{y}}$ & ML & $\mathrm{M}$ & MS & $\mathrm{S}$ & $\mathrm{L}$ & $\mathrm{ML}$ & $\mathrm{M}$ & MS & $\mathrm{S}$ \\
\hline \multirow[t]{6}{*}{ Nonpareil } & 0 & 1.00 & 1.00 & 0.97 & 0.92 & 0.92 & 3.50 & 4.29 & 5.00 & 4.94 & 5.23 \\
\hline & 1 & 1.00 & 0.95 & 0.42 & 0.00 & 0.00 & 19.11 & 11.33 & 4.00 & - & - \\
\hline & 2 & 0.89 & 0.68 & 0.18 & 0.00 & 0.00 & 25.38 & 15.92 & 6.43 & - & - \\
\hline & 3 & 0.95 & 0.87 & 0.34 & 0.18 & 0.08 & 10.39 & 13.58 & 12.46 & 12.14 & 9.00 \\
\hline & 4 & 1.00 & 1.00 & 0.89 & 0.74 & 0.29 & 31.37 & 23.58 & 16.03 & 7.11 & 3.91 \\
\hline & 5 & 0.95 & 0.97 & 0.97 & 0.95 & 0.97 & 1.92 & 2.32 & 2.76 & 2.83 & 2.59 \\
\hline \multirow[t]{6}{*}{ Aldrich } & 0 & 1.00 & 0.97 & 1.00 & 1.00 & 1.00 & 3.03 & 4.22 & 4.76 & 5.89 & 4.34 \\
\hline & 1 & 1.00 & 0.95 & 0.39 & 0.00 & 0.00 & 23.89 & 14.53 & 5.13 & - & - \\
\hline & 2 & 1.00 & 0.92 & 0.53 & 0.05 & 0.00 & 28.03 & 19.23 & 10.05 & 8.00 & - \\
\hline & 3 & 0.66 & 0.74 & 0.79 & 0.08 & 0.00 & 7.60 & 11.50 & 12.00 & 7.67 & - \\
\hline & 4 & 1.00 & 1.00 & 0.97 & 0.92 & 0.37 & 12.08 & 14.84 & 13.97 & 6.17 & 3.14 \\
\hline & 5 & 0.87 & 0.92 & 0.95 & 0.92 & 0.84 & 2.52 & 2.09 & 2.92 & 3.31 & 2.66 \\
\hline \multirow[t]{7}{*}{ Winters } & 0 & 0.97 & 1.00 & 0.97 & 1.00 & 1.00 & 4.78 & 6.16 & 5.84 & 5.84 & 5.11 \\
\hline & 1 & 1.00 & 0.74 & 0.11 & 0.00 & 0.00 & 8.18 & 7.64 & 3.25 & - & - \\
\hline & 2 & 1.00 & 0.74 & 0.11 & 0.00 & 0.00 & 11.29 & 16.25 & 7.25 & - & - \\
\hline & 3 & 0.97 & 0.95 & 0.29 & 0.11 & 0.00 & 10.22 & 11.61 & 8.64 & 7.25 & - \\
\hline & 4 & 1.00 & 0.68 & 0.16 & 0.00 & 0.00 & 39.05 & 18.15 & 8.17 & - & - \\
\hline & 5 & 1.00 & 1.00 & 1.00 & 1.00 & 0.84 & 15.92 & 26.47 & 25.03 & 11.42 & 3.69 \\
\hline & 6 & 1.00 & 0.87 & 0.89 & 0.82 & 0.87 & 1.76 & 2.03 & 1.91 & 2.26 & 2.70 \\
\hline
\end{tabular}

zZones of homogenous observation types from Zone 0 (at the top) to Zone 5 (at the base) of 2-year-old shoots in 'Nonpareil' and 'Aldrich' and to Zone 6 (at the base) of 2-year-old shoots in 'Winters'. ${ }^{y}$ Shoot length categories were L [long (more than $\left.100 \mathrm{~cm}\right)$ ], ML [medium-long (60 to $\left.100 \mathrm{~cm}\right)$ ], M [medium $(20$ to $60 \mathrm{~cm})$ ], MS [medium-short $(5$ to $20 \mathrm{~cm})$ ], and S [short (less than $5 \mathrm{~cm})$ ].
Zones located in the same ordinal position along the shoots in these two cultivars were composed of the same observation types with only some differences in their probability given by the observation distributions, except for Zone 4. In this zone, 'Aldrich' only developed spurs and blind nodes and lacked the proleptic and sylleptic shoots seen in 'Nonpareil'. In addition, spurs had a higher probability of occurrence in 'Aldrich' in ery zone than in 'Nonpareil'. The probabilities of occurrence pareil' (Table 2); i.e., zones at the base and at the tip of the shoots had high and relatively constant probabilities of occurrence, whereas the probabilities of other zones decreased along the lengths of the shoots. The mean number of nodes of the zimilar patterns as in 'Nonpareil' (Table 2), i.e., the number of nodes was more constant in zones with mainly blind nodes than in other zones, where the number of odes decreased along with shoot length. In addition, the two 'Aldrich' than in 'Nonpareil'. Zones 3 and 4, located toward the base of the shoots, had fewer nodes in 'Aldrich' than the same zones in 'Nonpareil'.

'Winters' was modeled differently from the other cultivars using an eight-state hidden semi-Markov model (Fig. 3C). This model had four transient states representing successive branching zones, three recurrent states, which corresponded to three ones with distinct characteristics that could be found more we 3-year-old shoot. Although zones at the basal part of the shoots were reiterative, the distal part of the shoot developed zones with similar characteristics and patterns in the other two cultivars. Zones with blind nodes were located at the base and at the tip of the shoots. Zone 1 was composed of proleptic shoots, blind nodes, and spurs, like in the other cultivars, but the probability of blind nodes was higher in 'Winters'. Zone 2 was composed of the same observations as the other two cultivars, but the probabilities of proleptic and sylleptic shoots were higher than the probability of blind nodes, contrary to the other cultivars. Zone 3 was composed of blind nodes and spurs and had the same observation distribution as in 'Nonpareil'. The following zone was composed of the same observations as Zone 2 but had a higher occurrence of sylleptic shoots than in Zone 2. The composition of this zone was more similar to Zone 4 in 'Nonpareil' than in 'Aldrich' but had a higher probability of sylleptic shoots than in 'Nonpareil'. Zone 5 was composed of spurs and blind nodes and had a very similar distribution of observations as Zone 4 in 'Aldrich'. In 'Winters', Zone 5 was located next to Zone 6 (composed of blind nodes) in $49 \%$ of the shoots and had the same location as Zone 4 in 'Aldrich' at the base of the shoot. In $44 \%$ of the shoots, Zone 5 was 
located next to Zone 3, and the subsequent recurrence of Zones 4 and 5 toward the base of the shoots was determined by transition probabilities. These three zones could be repeated up to three times on each shoot (data not shown). The occurrence of every zone was high on long shoots, and central zones were less present as shoots decreased in length, like in the other cultivars (Table 2). The number of nodes of each zone was variable among shoots of different length categories, except for the basal and apical blind zones, which had similar numbers of nodes (Table 2). The number of nodes of the central zones did not always decrease along with shoot length. Zone 4 that had higher probability of sylleptic shoots had more nodes in long shoots than in medium-long and medium shoots. On the other hand, Zone 5 that was composed mainly of spurs has more nodes in medium-long and medium shoots than in long shoots.

The number of flower buds on the 2-year-old proleptic shoots also varied among cultivars (Table 3 ). 'Aldrich' had more flower buds on long, medium, and medium-short shoots than 'Nonpareil' and more flower buds on medium and medium-short shoots than 'Winters'. In addition, the number of flower buds in 'Aldrich' was similar to 'Nonpareil' and 'Winters' on medium-long and short shoots. No differences were observed by shoot length category between 'Nonpareil' and 'Winters'.

\section{Discussion}

In the three evaluated almond cultivars with distinctive tree architectures, this study identified differences among cultivars in lateral shoot type composition, branching pattern along the shoots, and flower bud number of the different shoot length categories. In 'Nonpareil' and 'Aldrich', the branching patterns of 2-year-old shoots were represented by two similar models that described six successive zones along the shoots, whereas 'Winters' branching patterns were quite different from the other two cultivars (Fig. 3). In 'Nonpareil' and 'Aldrich', zones with similar observation type composition were located in the same positions in terms of order. That is, blind node zones were located at the tip, base, and middle (Zone 3). A proleptic shoot zone was situated toward the tip of the shoots below the blind apical zone, and spurs combined with some branching were located closer to the basal zone. The common locations between these cultivars of the zones along the shoots suggest that the development of the different observation types was expressed in the same order during the growing season. In 'Winters', although the composition of the four apical zones

Table 3. Mean number of flower buds on 2-year-old shoots (including flower buds on 1-year-old spurs and on 1-year-old proleptic and sylleptic shoots) of five different shoot length categories (L, ML, $\mathrm{M}, \mathrm{MS}, \mathrm{S}$ ) in three almond cultivars (Nonpareil, Aldrich, Winters) in Feb. 2010.

\begin{tabular}{lcrrcc}
\hline Cultivar & $\mathrm{L}^{\mathrm{z}}$ (no.) & ML (no.) & M (no.) & MS (no.) & $\mathrm{S}$ (no.) \\
\hline Nonpareil & $220.37 \mathrm{~b}^{\mathrm{y}}$ & $88.63 \mathrm{a}$ & $16.23 \mathrm{~b}$ & $1.66 \mathrm{~b}$ & $0.03 \mathrm{a}$ \\
Aldrich & $322.82 \mathrm{a}$ & $103.37 \mathrm{a}$ & $29.68 \mathrm{a}$ & $9.95 \mathrm{a}$ & $0.42 \mathrm{a}$ \\
Winters & $245.87 \mathrm{ab}$ & $104.89 \mathrm{a}$ & $19.15 \mathrm{~b}$ & $2.82 \mathrm{~b}$ & $0.11 \mathrm{a}$
\end{tabular}

${ }^{\mathrm{z}}$ Shoot length categories were L [long (more than $100 \mathrm{~cm}$ )], ML [medium-long $(60$ to $100 \mathrm{~cm})$ ], M [medium $(20$ to $60 \mathrm{~cm})$ ], MS [medium-short (5 to $20 \mathrm{~cm}$ )], and S [short (less than $5 \mathrm{~cm}$ )].

${ }^{y}$ Letter indicates difference among cultivars for each shoot length category according to the Wilcoxon-Mann-Whitney test at $P \leq 0.05$. was similar to the other cultivars, reiteration of three other zones was observed on the basal part of the shoots.

Similarity in branching patterns between 'Nonpareil' and 'Aldrich' can be genetically explained by their common origin. In California, most recently developed cultivars are highly inbred and have 'Nonpareil' and/or 'Mission' in their parental lineage, and these two cultivars also appear to be related and derived from common germplasm in the Languedoc region of France (Dangl et al., 2009; Gradziel, 2011). For 'Winters', germplasm different from that found in California was incorporated to increase breeding options and to decrease the genetic vulnerability of almond cultivars. Incorporation of novel germplasm in the development of 'Winters' apparently contributed to its different branching patterns (Gradziel, 2012).

Branching is a function of apical dominance, which controls the inhibition of sylleptic shoot growth during the first growing season, and apical control, which inhibits the growth of proleptic shoots during the second growing season (Brown et al., 1967). However, apical dominance effects on the outgrowth of lateral shoots can be modified when the main shoot is relatively horizontal (Wareing and Nasr, 1961). The presence of proleptic shoots at the distal part of the shoots indicated that 'Nonpareil' and 'Aldrich' tend to be acrotonic (Fig. 3). However, in 'Nonpareil', some proleptic and sylleptic shoots developed in the proximal part of the shoots, indicating that this cultivar also has basitonic tendencies. 'Winters' shoots showed mesotonic characteristics because sylleptic and proleptic shoots were distributed more evenly along the shoots (Fig. 3). In 'Winters', abundant lateral sylleptic shoots developed during the first growing season and limited proleptic branching occurred during the second season in long, mediumlong, and medium shoots (Table 1). This indicates that less apical dominance was apparently exerted, whereas shoot growth was most active in this cultivar. In addition, development of sylleptic shoots has been previously related to rapid parent shoot growth rate in peach [Prunus persica (Génard et al., 1994; Hipps et al., 1995)]; thus, more rapid growth rates may have occurred in this cultivar than in the others. In addition, the acrotonic, mesotonic, or basitonic distribution of branching along the shoots have been explained as the result of the equilibrium of auxin and cytokinins (Cook et al., 2001; Solar et al., 2011; Tworkoski and Miller, 2007; Wilson, 2000). For example, strong acrotony has been reported when greater cytokinin content was concentrated in distal shoot parts before the basal part of the shoots in apple (Cook et al., 2001) and less branching was observed with higher concentrations of auxin in walnut shoots [Juglans regia (Solar et al., 2011)].

Not all lateral meristems were able to form sylleptic shoots in the different zones along the shoots, and instead some formed vegetative buds during the first season. Nor were all lateral meristems able to extend into proleptic shoots, but instead formed spurs in the second season (Fig. 3). It has been hypothesized that these phenomena can be explained by competition among the meristems for stored carbohydrates or assimilates (Oliveira and Priestley, 1988). In 'Winters', most of the nodes developed more spurs and fewer proleptic shoots than in the other cultivars. This could be possibly the result of competition for carbohydrates between the lateral (sylleptic) shoots and the later developing proleptic shoots or perhaps the collective presence of more terminal meristems on the 1-yearold 'Winters' branches increasing the amount of apical control exerted on proleptic branching (Brown et al., 1967). 
Although branching varied among cultivars, models showed that branching varied with the length of the parent shoots in similar ways in the different cultivars. Central zones were less present and had fewer nodes as shoots decreased in length and only zones with blind nodes or zones with blind nodes and spurs were observed on short shoots (Table 2). Similar results have been observed in apple, where shoot length also affected branching in similar ways, suggesting that the occurrence and number of nodes of the zones may be related to the vigor of the shoots (Renton et al., 2006). Although other studies also associated the lack of branching zones with the length of the shoots (Cannell, 1974; Harmer, 1992), variations between shoot length and branching suggested that variables other than the length of the shoots determined branching (Harmer, 1992). Among those variables are growth rate of the parent shoots (Génard et al., 1994), apical dominance and apical control (Brown et al., 1967), and genotype-specific responses to the environment (Fournier et al., 2003).

The hidden semi-Markov model technique was useful for the identification of homogenous zones of branching along the shoots as well as common zones among shoots of different lengths (Fig. 3). The hidden semi-Markov model showed that the zone distributions of the different observation types along the shoots in 'Nonpareil' and 'Aldrich' were similar to those observed in different apple cultivars (Costes and Guédon, 2002), except that almond lacks shoots with terminal flowers that are present in apple. Thus, branching is probably regulated by similar processes in different species. These models have been consistent in identifying architectural patterns of different cultivars under the same horticultural and climatic conditions. In the future it would be interesting to determine how consistent those patterns are under different conditions.

The bloom evaluation of 2-year-old shoots indicated that 'Aldrich' had more or equal numbers of flower buds in each shoot category compared with the other cultivars (Table 3). This agrees with previous descriptions of the cultivar indicating that it blooms heavily (Aldrich, 1984). Despite the similarities between 'Nonpareil' and 'Aldrich' in the shoot branching patterns as well as in the number of spurs and lateral shoots, fewer flowers buds were present in 'Nonpareil' (Table 3). 'Winters' shoots had different patterns than 'Aldrich' with more spurs and sylleptic shoots, but 'Winters' shoots did not produce more flower buds. Therefore, a certain type of branching pattern (as the one described for 'Nonpareil' and 'Aldrich') or another with more spurs and sylleptic shoots (as the one described for 'Winters') did not necessarily translate into more flower buds that year, suggesting that characteristics other than branching are more important for determining cropping potential. For example, leaf area has been reported to have a strong correlation with flowering (Lampinen et al., 2011).

This study showed that almond cultivars with dissimilar tree architectures can have similar branching patterns as in the case between 'Nonpareil' and 'Aldrich' or different as in the case of 'Winters', which had more distinct zones, spurs, and sylleptic shoots. However, all cultivars had similar simplification of the branching patterns as shoot lengths decreased. The branching patterns of the shoots did not define flowering at the shoot level because similar branching patterns had differences in flowering. The models built on these cultivars can be useful to identify branching pattern similarities with other cultivars and selections; however, flowering can vary in each branching pattern.

\section{Literature Cited}

Aldrich, C.E. 1984. Almond tree. US Patent PP05,320. Patent and Trademark Office, Washington, DC.

Asai, W.K., W.C. Micke, D.E. Kester, and D. Rough. 1996. The evaluation and selection of current varieties, p. 52-60. In: Micke, W.C. (ed.). Almond production manual. Univ. California, Oakland, CA. Barthélémy, D. and Y. Caraglio. 2007. Plant architecture: A dynamic, multilevel and comprehensive approach to plant form, structure and ontogeny. Ann. Bot. (Lond.) 99:375-407.

Bernad, D. and R. Socias i Company. 1998. Bud density and shoot morphology of some self-compatible almond selections. Acta Hort. 470:273-279.

Brown, C.L., R.G. McAlpine, and P.P. Kormanik. 1967. Apical dominance and form in woody plants: A reappraisal. Amer. J. Bot. 54:153-162.

Cannell, M.G.R. 1974. Production of branches and foliage by young trees of branches and foliage by young trees of Pinus contorta and Picea sitchensis: Provenance differences and their simulation. J. Appl. Ecol. 11:1091-1115.

Cook, N.C., D.U. Bellstedt, and G. Jacobs. 2001. Endogenous cytokinin distribution patterns at budburst in Granny Smith and Braeburn apple shoots in relation to bud growth. Sci. Hort. 87: 53-63.

Costes, E. and Y. Guédon. 1996. Modelling the annual shoot structure of the apricot tree 'Lambertin' in terms of axillary flowering and vegetative growth. Acta Hort. 416:21-28.

Costes, E. and Y. Guédon. 1997. Modeling the sylleptic branching on one-year-old trunks of apple cultivars. J. Amer. Soc. Hort. Sci. 122:53-62.

Costes, E. and Y. Guédon. 2002. Modelling branching patterns on 1-year-old trunks of six apple cultivars. Ann. Bot. (Lond.) 89:513524.

Costes, E., P.É. Lauri, and J.L. Regnard. 2006. Analyzing fruit tree architecture: Implications for tree management and fruit production. Hort. Rev. 32:1-61.

Dangl, G.S., J. Yang, D.A. Golino, and T. Gradziel. 2009. A practical method for almond cultivar identification and parental analysis using simple sequence repeat markers. Euphytica 168:41-48.

Fisher, J.B. 1984. Tree architecture: Relationships between structure and function, p. 541-589. In: White, R.A. and W.C. Dickison (eds.). Contemporary problems in plant anatomy. Academic Press, Orlando, FL.

Fournier, D., E. Costes, J.C. Salles, V. Segura, G. Clauzel, J.M. Audergon, and J.M. Legave. 2003. Analysis of morphological and architectural traits of apricot cultivars grown in different environmental conditions. Acta Hort. 663:375-380.

Génard, M., L. Pagès, and J. Kervella. 1994. Relationship between sylleptic branching and components of parent shoot development in the peach tree. Ann. Bot. (Lond.) 74:465-470.

Godin, C., Y. Guédon, E. Costes, and Y. Caraglio. 1997. Measuring and analyzing plants with the AMAPmod software, p. 63-94. In: Michalewicz, M.T. (ed.). Plants to ecosystems: Advances in computational life sciences. CSIRO, Melbourne, Australia.

Gradziel, T.M. 1997. Almond, p. 1-12. In: Brooks, R.M. and H.P. Olmo (eds.). The Brooks and Olmo register of fruit and nut varieties. 3rd Ed. ASHS Press, Alexandria, VA.

Gradziel, T.M. 2011. Origin and dissemination of almond. Hort. Rev. 38:23-81.

Gradziel, T.M. 2012. The utilization of wild relatives of cultivated almond and peach in modifying tree architecture for crop improvement. Acta Hort. 948:271-278.

Gradziel, T.M., D.E. Kester, and P. Martínez-Gómez. 2002. A development based classification for branch architecture in almond. J. Amer. Pomol. Soc. 56:106-112.

Gradziel, T.M., B. Lampinen, J.H. Connell, and M. Viveros. 2007. 'Winters' almond: An early-blooming, productive, and high-quality pollenizer for 'Nonpareil'. HortScience 42:1725-1727. 
Guédon, Y., D. Barthélémy, Y. Caraglio, and E. Costes. 2001. Pattern analysis in branching and axillary flowering sequences. J. Theor. Biol. 212:481-520.

Hallé, F., R.A.A. Oldeman, and P.B. Tomlinson. 1978. Tropical trees and forests: An architectural analysis. Springer-Verlag, Berlin, Germany.

Harmer, R. 1992. Relationships between shoot length, bud number and branch production in Quercus petraea (Matt.) Liebl. Forestry 65:61-72.

Hipps, N.A., L. Pagès, J.G. Huguet, and V. Serra. 1995. Influence of controlled water supply on shoot and root development of young peach trees. Tree Physiol. 15:95-103.

Kester, D.E., T.M. Gradziel, and C. Grasselly. 1991. Almonds (Prunus), p. 701-758. In: Moore, J.N. and J.R. Ballington (eds.). Genetic resources of temperate fruit and nut crops. Intl. Soc. Hort. Sci., Wageningen, The Netherlands.

Kester, D.E., G.C. Martin, and J.M. Labavitch. 1996. Growth and development, p. 90-97. In: Micke, W.C. (ed.). Almond production manual. Univ. California, Oakland, CA.

Lampinen, B.D., S. Tombesi, S.G. Metcalf, and T.M. DeJong. 2011. Spur behaviour in almond trees: Relationships between previous year spur leaf area, fruit bearing and mortality. Tree Physiol. 31:700-706.

Oliveira, C.M. and C.A. Priestley. 1988. Carbohydrate reserves in deciduous fruit trees. Hort. Rev. 10:403-430.

Polito, V.S., K. Pinney, R. Heerema, and S.A. Weinbaum. 2002. Flower differentiation and spur leaf area in almond. J. Hort. Sci. Biotechnol. 77:474-478.
Pradal, C., S. Dufour-Kowalski, F. Boudon, C. Fournier, and C. Godin. 2008. OpenAlea: A visual programming and component-based software platform for plant modelling. Funct. Plant Biol. 35:751760.

Renton, M., Y. Guédon, C. Godin, and E. Costes. 2006. Similarities and gradients in growth unit branching patterns during ontogeny in 'Fuji' apple trees: A stochastic approach. J. Expt. Bot. 57:31313143.

Solar, A., G. Osterc, F. Štampar, and D. Kelc. 2011. Branching of annual shoots in common walnut (Juglans regia $\mathrm{L}$.) as affected by bud production and indole-3-acetic acid (IAA) content. Trees (Berl.) 25:1083-1090.

Tworkoski, T. and S. Miller. 2007. Endogenous hormone concentrations and bud-break response to exogenous benzyl adenine in shoots of apple trees with two growth habits grown on three rootstocks. J. Hort. Sci. Biotechnol. 82:960-966.

U.S. Department of Agriculture. 2011. California almond acreage report for 2011. U.S. Dept. Agr., Sacramento, CA.

Wareing, P. and T. Nasr. 1961. Gravimorphism in trees 1. Effects of gravity on growth and apical dominance in fruit trees. Ann. Bot. (Lond.) 25:321-340.

Weinbaum, S.A. and P. Spiegel-Roy. 1985. The almond, p. 139-146. In: Halevy, A.H. (ed.). Handbook of flowering. CRC Press, Boca Raton, FL.

Wilson, B.F. 2000. Apical control of branch growth and angle in woody plants. Amer. J. Bot. 87:601-607. 